\title{
SCIDOC
}

\author{
International Journal of Dentistry and Oral Science (IJDOS) \\ ISSN: $2377-8075$
}

\section{Infection Control In Dental Practice During Covid-19 Pandemic: A Questionnaire Based Cross Sectional Study}

S. Hema Nandhini ${ }^{1 *}$, Haribabu Ramasamy ${ }^{2}$, Vennila Anand ${ }^{3}$

${ }^{1}$ Assistant Professor, Department of Prosthodontics, Sathyabama Dental College and Hospital, Chennai-600129, India.

${ }^{2}$ Professor \& Head of the Department, Department of Prosthodontics, Sathyabama Dental College and Hospital, Chennai-600129, India.

${ }^{3}$ Epidemiology, TamilNadu, Dr.MGR University, Chennai-600032, India.

\section{Abstract}

Objective: In the event of an outbreak, the dentist can be the first person to come in contact with an infected person; they can either unknowingly become a carrier and infect others or by following proper guidelines can prevent the possible spread of the disease and save the entire community from its disastrous consequences. The aim of this study is to assess the awareness of COVID-19 disease related infection control practices among dentists and dental students.

Materials And Methods: An online questionnaire was distributed among dentists and dental students on COVID-19 awareness and infection control among dentists. The questionnaire was divided into 4 sections: the 1st one contained an informed consent form, the 2nd, 3rd, 4th sections had the demographic details (9 questions), COVID 19 Awareness (10 questions), Infection control (10 questions). The data was analysed using Epi info (version 7.2.2.6, CDC, license: public domain) software with frequency distribution, descriptive statistics and chi square test.

Results: A total of 316 responders completed the questionnaire based survey on COVID-19 awareness and infection control among dentists. About 77.8\% participants (245) have good knowledge and 22.2\% (70) participants have fair knowledge regarding COVID 19 awareness and infection control.

Conclusion: The dentists were found to have good knowledge and practice scores, which is important to combat COVID-19. They are advised to follow the Centres of Disease Control and Prevention (CDC) and World Health Organization (WHO) guidelines in their clinics, and sensitize their staff so that no stone is left unturned in defeating this pandemic.

Keywords: Covid-19; Infection Control; Dentist; Dental Practice; Pandemic.

\section{Introduction}

The novel coronavirus belongs to a family of single-stranded RNA viruses known as Coronaviridae [1]. This family of viruses are known to be zoonotic or transmitted from animals to humans [2]. As the published genome sequence for this novel coronavirus has a close resemblance with other beta-coronaviruses such as SARS-CoV and MERS-CoV, the Coronavirus Study Group of the International Committee on Taxonomy of Viruses has given it the scientific name SARS-CoV-2, even though it is popularly called the COVID-19 virus $[1,2]$.

In December 2019, the 2019 novel coronavirus disease (COV-
ID-19) caused by novel severe acute respiratory syndrome coronavirus 2 (SARS-CoV-2) emerged in China, followed by a rapid spread all over the world. On March 11, 2020, the World Health Organization (WHO) raised its pandemic alert. As of March 2021, COVID-19 had caused over 122,992,844 confirmed cases and 2,711,071 deaths in 189 countries and overseas territories or communities [3].

A large number of medical staff were reported to have acquired the disease while working with infected individuals. The dental clinic is not an exception for a similar possibility of transmitting and acquiring the infection between staff or individuals; moreover, the dental clinic could be a riskier environment for spreading

*Corresponding Author

Dr. S. Hema Nandhini. MDS,

Assistant Professor, Department of Prosthodontics, Sathyabama Dental College and Hospital, Chennai-600129, India.

Tel: 09994303663

Email ID: dr.hema.nandhini@gmail.com

Received: March 23, 2021

Accepted: May 07, 202

Published: May 11, 202

Citation: S. Hema Nandhini, Haribabu Ramasamy, Vennila Anand. Infection Control In Dental Practice During Covid-19 Pandemic: A Questionnaire Based Cross Sectional Study. Int J Dentistry Oral Sci. 2021;08(5):2427-2432. doi: http://dx.doi.org/10.19070/2377-8075-21000478

Copyright: S. Hema Nandhini. MDS ${ }^{\top} 2021$. This is an open-access article distributed under the terms of the Creative Commons Attribution License, which permits unrestricted use, distribution and reproduction in any medium, provided the original author and source are credited. 
the virus because of the close contact with patients and the nature of the dental treatment [4].

Aerosols are defined as liquid or solid particles suspended in the air by humans, animals, instruments, or machines. Aerosols, which are responsible for the transmission of airborne micro-organisms by air, consist of small particles named droplet nuclei $(1-5 \mu \mathrm{m})$ or droplets $(>5 \mu \mathrm{m})$. Droplet nuclei can stay airborne for hours, transport over long distances and contaminate surfaces by falling down [5]. Patients infected with COVID-19, without showing symptoms, are of a great threat to dentists and other members of the dental team. Dentists, thereby, should entertain a high level of awareness and integrity to deal with the disease and be able to control and manage its spread [4].

Patients diagnosed with COVID-19 have the relatively prolonged incubation period of the disease [the median incubation period was estimated to be 5.1 days, 95\% CI 4.5-5.8 [6] or up to 14 days for some cases $[7,8]$ before any symptoms could even be detected] and the post infection period make it challenging for medical staff to recognize the existence of COVID-19 infections, which could increase the transmission of the disease during these lay periods. Therefore, patients infected with COVID-19, without showing symptoms, are of a great threat to dentists and other members of the dental team. Dentists, thereby, should entertain a high level of awareness and integrity to deal with the disease and be able to control and manage its spread [4].

There are practical guidelines recommended for dentists and dental staff by the Centres for Disease Control and Prevention (CDC), Dental council of India (DCI), the Indian Dental Association (IDA), and the World Health Organization to control the spread of COVID-19. It is important to implement sound prevention measures in dental clinics and to increase the level of awareness among dentists to improve their prevention. Hence, this study aimed to assess the level of awareness and infection control against COVID-19 among Indian dentists [4].

\section{Material and Methods}

This was a questionnaire-based survey adapted from current interim guidelines and information for dentists provided by the WHO, US Centres for Disease Control and Prevention (CDC), IDA and DCI [9-11]. We performed a cross-sectional survey of a convenient sample of respondents. This survey was conducted in April 2020. An online questionnaire using Google Forms was used to collect the data.

However, each participant who was randomly selected was contacted individually to make sure that they were a dentist. The questionnaires were anonymous to maintain the privacy and confidentiality of all information collected in the study. Ethical approval was obtained from the Institutional Review Board at Sathyabama institute of Science and Technology.

The questions on the survey were developed after reviewing pertinent literature and the international guidelines [9-11]. The questionnaire was designed in English and comprised of a series of questions pertaining to socio-demographic characteristics, the knowledge of dentists, and their attitudes and perceptions toward COVID-19 and infection control in dental clinics. The survey was a structured multiple choice questionnaire divided into sections: The questionnaire was divided into 4 sections: the 1 st one contained an informed consent form, the 2nd, 3rd, 4th sections had the demographic details (9 questions), COVID 19 Awareness (10 questions), Infection control against Covid-19(4 questions). Descriptive statistics was performed for all the groups and subgroups.

Simple random sampling method was used for data collection and the distribution of responses was presented as frequency and percentages. Sub-groups were classified on the basis of gender, age (18-30 years, $31-45$ years, and $>45$ years) and profession (undergraduate, graduate students and faculty from dental colleges and clinical practioners). Data were tabulated in excel, and descriptive statistics were performed using Epi info (version 7.2.2.6, CDC, license: public domain) software.

\section{Results And Discussion}

\section{Results}

This study included a total of 316 dentists and dental students. Their age ranged from 21-60 years with the maximum of 215 $(68.3 \%)$ dentists in the age group of $21-30$ years. The gender distribution was predominantly female $223(70.8 \%)$

A total of $178(56.5 \%)$ were undergraduate dental students, $69(21.9 \%)$ were postgraduate dentists. Years of dental practice ranged from $<1$ year, 1-5 years, 5-10 years, $10-15$ years and $>15$ years, of which $175(55.6 \%)$ were dental students and dentists with an experience ranging from 5-10 years were 64 (20.3\%).

A total of $233(73.9 \%)$ dentists were working in educational institutions and $100(31.7 \%)$ were working in dental clinics. Of which majority of the dentists were attached to private sectors $290(92.1 \%)$ Based on the place of work, 246 (78.1\%) were working in urban and 53(16.8\%) were working in semi-urban. (Table 1)

\section{Awareness about the virus, Signs and symptoms, Mode of transmission}

When asked about the virus causing corona virus disease 162 $(50.8 \%)$ reported as SARS-CoV2 and 135(42.3\%) reported as 2019-nCoV. Most of them correctly reported Wuhan, China $313(99.3 \%)$ as the place Covid-19 was first diagnosed. The percentage of dentists who reported the different symptoms of the COVID-19 infection mode of transmission (Table 2). Majority of the dentists reported fever, dry cough $310(98.4 \%)$ and $291(92.3 \%)$ reported shortness of breath, 242(76.8\%) reported sore throat as symptoms. Mode of transmission was reported as coughing and sneezing by 295(93.6\%) dentists and $274(86.9 \%)$ dentists reported hand shaking or touching surfaces such as doorknobs and tables (Figure 1).

\section{Infection control and Treatment of Patients with COVID-19}

On discussing about preparing the waiting room for infection control in dental clinic 291 (91.5\%) dentists reported that routine cleaning and disinfecting the surfaces in contact with known or suspected patients and $278(87.4 \%)$ dentists said placing chairs 
3-6 feet apart with physical barriers is essential. Precautionary actions that needs to be taken by the patient in dental practice was reported as wearing masks in the waiting room by $305(95.9 \%)$ and $286(89.9 \%)$ reported that patients must be asked to sit far from each other, $283(89 \%)$ of the dentists chose that patients must be asked to wash hands before getting in the dental chair (Table 3).

\section{Attitude towards treatment of patients with COVID-19}

Majority of the dentists reported that the dental procedures that required priority care during lockdown are un-controlled bleeding or dental or facial trauma obstructing airway by $303(95.3 \%)$ dentists while $252(79.2 \%)$ dentists reported that cellulitis or diffuse bacterial infections with edema to be treated as priority. On asking dentists what they would do if the patient is sneezing and coughing in clinic, $219(68.9 \%)$ dentists reported that the patient must be referred to the hospital without treating them .It was also reported that the most efficient Personal protection of the dentist to prevent exposure was to wear personal protective equipment such as dental goggles, masks and gloves by 290 (91.2 \%) dentists. While 267 (84\%) dentists reported that using N95 respirators, FFP3-standard mask to be used while treating dental patients is essential.

\section{Clinical management of patient}

Taking a detailed travel $\&$ health history, contact details $\&$ address of all patients is reported as the most efficient way to manage by
$290(91.2 \%)$ dentists, whereas, taking temperature readings as part of the routine assessment of patients was reported as the efficient clinical management by $288(90.6 \%)$ dentists.

\section{Discussion}

We present here a study to assess the awareness of COVID-19 disease, infection control methods among dentists and dental students with a comparison of many features among them. It is heartening to note that the knowledge with respect to COVID-19 is relatively high among the respondents.

An online questionnaire was distributed among dentists and dental students on COVID-19 awareness, prevention and infection control among dentists. The questionnaire was divided into 4 sections: the 1st one contained an informed consent form, the 2nd, 3rd, 4th sections had the demographic details (10 questions), COVID 19 Awareness (10 questions), Infection control against Covid-19(10 questions) with a total of 25 questions .Scores were allotted for each question with a total of 50 marks. The respondents were categorised into fair (18-34), good (35-51) and poor $(<17)$ based on the score obtained.

Majority of the respondents scored Fair (27\%) and good (73\%). Whereas only a hand full of respondents scored poor. Statistical analysis was done, frequency percentage (\%), crosstab analysis and chi square test were used to portray the characteristics of the participant.

Figure 1. Shows frequency distribution of mode of transmission according to study participants.

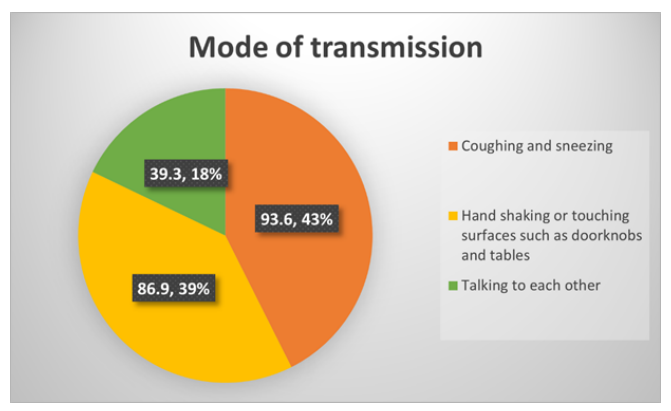

Figure 2. Shows gender, qualification and work place distribution of the study participants.

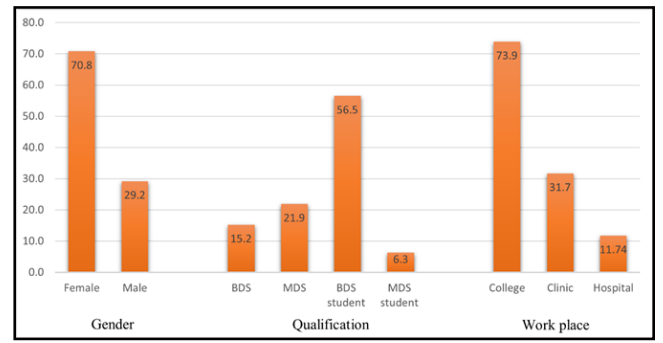

Figure 3. Shows frequency distribution of Source of information regarding COVID-19.

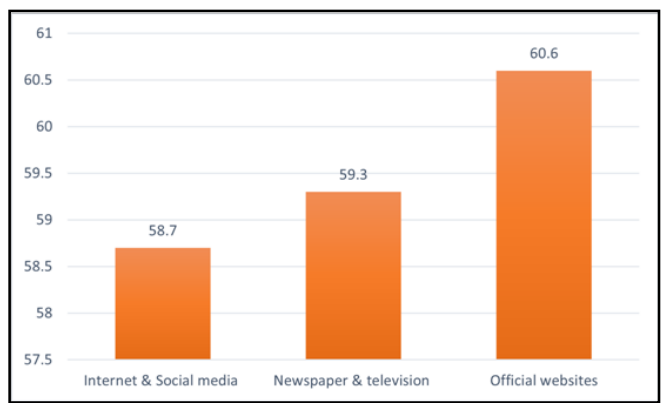


Table 1. Shows demographic details of the participants.

\begin{tabular}{|c|c|c|}
\hline VariableDentist (n) & & $\%$ \\
\hline Signs and symptoms & & \\
\hline Fever, dry cough & 310 & 98.4 \\
\hline Shortness of breath & 291 & 92.3 \\
\hline Diarrhoea & 106 & 33.6 \\
\hline Running nose & 117 & 37.1 \\
\hline Sore throat & 242 & 76.8 \\
\hline Conjunctivitis & 53 & 16.8 \\
\hline Skin rash & 45 & 14.2 \\
\hline Joint or muscle pain & 78 & 24.7 \\
\hline Chest pain & 73 & 23.1 \\
\hline May present with no symptoms & 2 & 0.6 \\
\hline Vomiting & 1 & 0.3 \\
\hline Mode of transmission & & \\
\hline Coughing and sneezing & 295 & 93.6 \\
\hline $\begin{array}{c}\text { Hand shaking or touching surfaces } \\
\text { such as doorknobs and tables }\end{array}$ & 274 & 86.9 \\
\hline Talking to each other & 124 & 39.3 \\
\hline
\end{tabular}

Table 2. Showing frequency distribution of signs \& symptoms and mode of transmission answered by participants.

\begin{tabular}{|c|c|c|}
\hline Variable & Dentist $(\mathrm{n})$ & $\%$ \\
\hline Age & & \\
\hline 21-30 years & 215 & 68.3 \\
\hline 31-40 years & 88 & 27.9 \\
\hline 41-50 years & 10 & 3.2 \\
\hline 51-60 years & 2 & 0.6 \\
\hline Gender & & \\
\hline Female & 223 & 70.8 \\
\hline Male & 92 & 29.2 \\
\hline Qualification & 48 & 15.2 \\
\hline Undergraduate dentist & 69 & 21.9 \\
\hline Postgraduate dentist & 178 & 56.5 \\
\hline Undergraduate dental student & 20 & 6.3 \\
\hline Postgraduate dental student & & \\
\hline Years of Dental Practice & 1 & 0.3 \\
\hline$<5$ years & 12 & 3.8 \\
\hline$>15$ years & 46 & 14.6 \\
\hline $1-5$ years & 17 & 5.4 \\
\hline $11-15$ years & 64 & 20.3 \\
\hline $5-10$ years & & 55.6 \\
\hline student & & \\
\hline
\end{tabular}

Females had significantly better knowledge statistically than males $(\mathrm{P}=0.610)[4,12]$ On statistical analysis , chi square test revealed that out of 315 samples 223 were female and it was also proved that $161(72.2 \%)$ scored good and $62(27.8 \%)$ scored fair. Whereas among male participants, $69(75 \%)$ scored good and $23(25 \%)$ scored fair. Females were predominant in this sample, which was similar to other studies $[4,12]$ which explained that this might be because the number of female dentists in Jordan is higher than the number of male dentists based on the latest Jordan Dental Association statistics [13]. The $\mathrm{p}$ value was calculated as 0.610 which shows that gender role is statistically insignificant.

Based on the occupation, since all the samples were dentists and dental students, cross tabulation was done based on their educational qualification, in which $91.3 \%$ postgraduate dentists scored 
Table 3. Showing the infection control questions answered by the participants and its percentage.

\begin{tabular}{|c|c|c|}
\hline Variable & Dentist (n) & $\%$ \\
\hline \multicolumn{3}{|l|}{ Preparing waiting room for infection control in dental clinic } \\
\hline Post a visual alert sign board at the entrance \& provide supplies for respiratory hygiene & 231 & 72.6 \\
\hline Routinely clean and disinfect surfaces in contact with known or suspected patients & 291 & 91.5 \\
\hline Place chairs 3-6 feet apart with physical barriers & 278 & 87.4 \\
\hline Remove toys, reading material, other communal objects and clean them & 215 & 67.6 \\
\hline \multicolumn{3}{|l|}{ Precautionary actions to be taken by the patient in dental practice } \\
\hline Ask patients to sit far from each other & 286 & 89.9 \\
\hline wear masks while in the waiting room & 305 & 95.9 \\
\hline wash hands before getting in the dental chair & 283 & 89 \\
\hline No precaution required and could cause panic & 10 & 3.1 \\
\hline Include travel history while recording case history & 2 & 0.6 \\
\hline Avoid working with a patient with a suspected case of COVID-19 & 1 & 0.3 \\
\hline \multicolumn{3}{|l|}{ Dental situations which require priority care during lockdown } \\
\hline Acute dental pain (pulpitis) & 189 & 59.4 \\
\hline Cellulitis or diffuse bacterial infections with edema & 252 & 79.2 \\
\hline Uncontrolled bleeding OR dental or facial trauma obstructing airway & 305 & 95.9 \\
\hline Changing intra-canal medication & 38 & 11.9 \\
\hline \multicolumn{3}{|l|}{ Patient sneezing or coughing in clinic } \\
\hline Refer the patient to the hospital without treating them & 219 & 68.9 \\
\hline Refuse treating the patient and ask them to leave the clinic & 27 & 8.5 \\
\hline Treat the patient and ask them to go to the hospital & 114 & 35.8 \\
\hline \multicolumn{3}{|l|}{ Personal protection of the dentist to prevent exposure } \\
\hline Use N95 respirators ,FFP3-standard mask to be used while treating & 268 & 84.3 \\
\hline Personal protective equipment such as dental goggles, masks, and gloves & 285 & 89.6 \\
\hline Usual clinical apron is sufficient along with masks, gloves & 81 & 25.5 \\
\hline Disposable cover all gown -inner to be changed daily \& outer to be changed after each patient & 236 & 74.2 \\
\hline \multicolumn{3}{|l|}{ clinical management of patient } \\
\hline Take a detailed travel $\&$ health history, contact details $\&$ address of all patients & 293 & 93 \\
\hline Take temperature readings as part of the routine assessment of patients & 288 & 91.4 \\
\hline Have patients rinse with a $1 \%$ hydrogen peroxide solution before each appointment. & 221 & 70.1 \\
\hline Use a rubber dam and high-speed evacuation & 195 & 61.9 \\
\hline
\end{tabular}

good and $16.7 \%$ undergraduate dentist scored fair. When asked about the experience, $93.1 \%$ dentists with experience of more than 10 years scored good compared to $61.7 \%$ dental students who scored good. On comparing the workplace based on clinic, educational institution, and hospital, $35.9 \%$ working in educational institutions scored fair. Sufficient knowledge was significantly correlated with dentists attached to the government and private sector. On performing chi square test, $\mathrm{p}$ value was obtained as 0.556 which shows statistical insignificance (Figure 2).

In a changing world, both healthcare professionals and the general public need to have reliable and accurate sources of information. The questions were framed using information from the World Health Organization (WHO), Up to date, Indian Council of Medical Research (ICMR), Centre for Disease Control (CDC), National Institute of Health (NIH) NIH, and website resources. On questioning about the main source of information for the dentists, a majority of $60.6 \%$ claimed that various official websites such as WHO, ICMR, CDC, DCI, IDA, Govt. Of India for reliable information, this is an indicator of their faith in health organizations across the world. (Figure 3) At the time that the survey was conducted, online webinars via zoom or other applications were just beginning in India to educate clinicians searching for answers. This is not reflected in our current study due to many of the responses being filled before the same or the respondents not being part of these audiences. Social media at $58.7 \%$ is the least source for the respondents. Since social media is prone to fake news, it is heartening that dentists and dental students are not learning much from it [14].

\section{Conclusion}

The COVID-19 pandemic has affected the world in various ways. The deficiency of information, the need for accurate information, and the rapidity of its dissemination are important, as this pandemic requires the cooperation of entire populations. The rapid survey that we conducted had a good response and we show that dentists and dental students were quite well informed about the 
coronavirus. They are aware of the measures needed to be taken to reduce the spread of the disease. The knowledge present allows the authors to speculate that the lockdown in India would be effective. The public receives a large amount of information from official websites like WHO, ICMR, DCI, IDA, and the medical fraternity and government need to develop strategies to ensure that accurate information needs to spread in these forums. The awareness is quite high and it is important that the knowledge of communication channels be known and be kept at the topmost priority throughout the pandemic.

\section{References}

[1]. Coronaviridae Study Group of the International Committee on Taxonomy of Viruses. The species Severe acute respiratory syndrome-related coronavirus: classifying 2019-nCoV and naming it SARS-CoV-2. Nat Microbiol. 2020 Apr;5(4):536-544. Pubmed PMID: 32123347.

[2]. Ather A, Patel B, Ruparel NB, Diogenes A, Hargreaves KM. Coronavirus disease 19 (COVID-19): implications for clinical dental care. Journal of endodontics. 2020 May 1;46(5):584-95.

[3]. WHO Coronavirus (COVID-19) Dashboard / WHO Coronavirus Disease (COVID-19) Dashboard [Internet]. [cited 2021 Mar 12].

[4]. Khader Y, Al Nsour M, Al-Batayneh OB, Saadeh R, Bashier H, Alfaqih M, et al. Dentists' Awareness, Perception, and Attitude Regarding COVID-19 and Infection Control: Cross-Sectional Study Among Jordanian Dentists. JMIR Public Health Surveill. 2020 Apr 9;6(2):e18798. Pubmed PMID:

\section{9 .}

[5]. Zemouri C, de Soet H, Crielaard W, Laheij A. A scoping review on bioaerosols in healthcare and the dental environment. PLoS One. 2017 May 22;12(5):e0178007. Pubmed PMID: 28531183.

[6]. Lauer SA, Grantz KH, Bi Q, Jones FK, Zheng Q, Meredith HR, et al. The Incubation Period of Coronavirus Disease 2019 (COVID-19) From Publicly Reported Confirmed Cases: Estimation and Application. Ann Intern Med. 2020 May 5;172(9):577-582. Pubmed PMID: 32150748.

[7]. Backer JA, Klinkenberg D, Wallinga J. Incubation period of 2019 novel coronavirus (2019-nCoV) infections among travellers from Wuhan, China, 20-28 January 2020. Euro Surveill. 2020 Feb;25(5):2000062. Pubmed PMID: 32046819.

[8]. Li Q, Guan X, Wu P, Wang X, Zhou L, Tong Y, et al. Early Transmission Dynamics in Wuhan, China, of Novel Coronavirus-Infected Pneumonia. N Engl J Med. 2020 Mar 26;382(13):1199-1207. Pubmed PMID: 31995857.

[9]. Oral Health | CDC [Internet]. [cited $2021 \mathrm{Mar} 12$ ].

[10]. Welcome To DCI Portal [Internet]. [cited $2021 \mathrm{Mar} 12]$.

[11]. COVID-19 Clinical management: living guidance [Internet]. [cited 2021 Mar 12].

[12]. Asaad A, El-Sokkary R, Alzamanan M, El-Shafei M. Knowledge and attitudes towards Middle East respiratory sydrome-coronavirus (MERS-CoV) among health care workers in south-western Saudi Arabia. East Mediterr Health J. 2020 Apr 16;26(4):435-442. Pubmed PMID: 32338362.

[13]. Jordanian Dental Association | Jordanian Dental Association [Internet]. [cited 2021 Mar 12].

[14]. Parikh PA, Shah BV, Phatak AG, Vadnerkar AC, Uttekar S, Thacker N, et al. COVID-19 Pandemic: Knowledge and Perceptions of the Public and Healthcare Professionals. Cureus. 2020 May 15;12(5):e8144. Pubmed PMID: 32550063. 